\title{
A PSICOMOTRICIDADE NO PROCESSO DE APRENDIZAGEM
}

\author{
Beatriz Fernanda Ferreira BALTAZAR ${ }^{1}$ \\ Elaine Cristina RABELLO ${ }^{2}$ \\ Gleicione Ap ${ }^{\mathrm{a}}$ Dias Bagne de SOUZA ${ }^{3}$
}

Recebido em: 18/05/2014 - Aprovado em: 18/07/2014 - Disponibilizado em: 30/07/2014

RESUMO: Este artigo é um estudo sobre a relação da psicomotricidade com o processo de aprendizagem e o seu papel como meio de prevenção nas dificuldades de aprendizagem. É uma investigação sobre o papel do movimento e do corpo no desenvolvimento da criança.

Palavra-chave: Psicomotricidade. Movimento. Imagem corporal. Dificuldade de aprendizagem.

ABSTRACT: This study's article is about the relationship of pychomotility with the learning process and his paper as a prevention in learning dificulties. It's a investigation about the moviment paper and body in child's development.

Keywords: Pychomotility. Moviment. Body image. Dificulties learning.

\footnotetext{
${ }^{1}$ Graduada em Pedagogia e Pós-graduada em Psicopedagogia Institucional e Clínica.

${ }^{2}$ Graduada em Normal Superior e Pós-graduada em Psicopedagogia Institucional e Clínica.

${ }^{3}$ Mestre em Engenharia de Produção com ênfase em Mídia e Conhecimento e Doutora em Educação. 979

Revista da Universidade Vale do Rio Verde, Três Corações, v. 12, n. 1, p. 979-987, jan./jul. 2014
} 


\section{Introdução}

Muitas são as queixas das escolas atualmente em relação às dificuldades de aprendizagem, que nos trazem não só problemas pedagógicos, como também problemas econômicos e sociais. Devido à sociedade competitiva, onde o diploma é um fator importantíssimo para a sobrevivência social, a escola é um dos lugares onde acontecem os processos de seleção social. Ela cria uma noção de aluno perfeito que constitui aspirações de pais e professores e vive em constante tentativa de concretizar isso através de processos pedagógicos que muitas vezes repercutem negativamente nos seres mais sensíveis: as crianças.

É muito importante que a escola veja a criança como ser integral, que está em constante processo de aprendizagem e o resultado satisfatório desse processo está ligado a muitos fatores.

Como ser cognoscente, é um ser pluridimensional, isto é, tem uma dimensão racional que constrói suas próprias estruturas por meio de sua ação sobre o objeto, uma dimensão relacional a medida que é um ser contextualizado, determinado pelas condições de sua existência em sociedade, e uma dimensão afetiva a medida que é determinado por um saber que é instituído pelas emoções do desejo.

Isso nos leva a consciência de que a aprendizagem passa pelo sentido, ou seja, a criança aprende aquilo que é significativo e tem ligação com sua realidade. E só será valorizado aquilo que ela é capaz de participar ativamente da construção. Portanto podemos a partir dessa ideia perceber a importância da relação do corpo, do movimento, da ação e da psicomotricidade no processo de aprendizagem. E que a posição da escola deve ser a de proporcionar o sucesso nesse processo, prevenindo as dificuldades de aprendizagem e dando ênfase nos trabalhos de desenvolvimento psicomotor principalmente nos primeiros anos de experiência escolar da criança.

\section{A influência do movimento no desenvolvimento humano}

O desenvolvimento humano tem como principal elemento o movimento.

Todo ato motor provém de uma ação e uma significação. Mesmo quando a criança está nos seus estágios mais primitivos, na fase dos movimentos reflexos, que são executados, independente da vontade, toda a ação depende de um estímulo que gere essa ação colocando assim a criança sempre em relação a algo.

Com a maturação motora o bebê abandona certas reações e se apropria de novos esquemas dando continuidade ao seu desenvolvimento. Através dos movimentos reflexos a criança ganha informação sobre o meio ambiente externo, reagindo aos estímulos como toque, luz e som com movimentos primeiramente involuntários, que imprimirão nesse corpo sensações prazerosas 
e desprazerosas, que auxiliarão as aprendizagens futuras.

Depois que a criança passa pelo estado de domínio afetivo entra no estado de caráter mais subjetivo: o sensorial.

Prova de que a expressão motora encontra-se ligada à esfera afetiva é que os primeiros movimentos úteis do bebê são os de expressão para tomar objetos indispensáveis ao seu bem estar.

A descoberta deste poder agir, associada ao poder sentir, vai trazer uma nova dimensão ao prazer primitivo do movimento. É o prazer da ação, o prazer de pegar o objeto e dar-lhe movimento, de deslocá-lo de lançá-lo, de modificar sua forma, de fazer barulho com ele (LAPIERRE, 1986, p.17).

A criança se comunica e expressa suas dificuldades de ordem motora, emocional ou cognitiva mediante sua relação com os objetos e com as pessoas, ou seja, através do movimento.

As estruturas do comportamento humano acontecem primeiramente de ordem motora e só mais tarde de ordem mental.

$\mathrm{O}$ enriquecimento do contato do ser humano com o meio o leva à consciência, e com o papel da motricidade podemos perceber que o desenvolvimento da inteligência do bebê se dá através da atividade e do movimento, e é através dele que as estruturas do comportamento são elaboradas.

A adaptação do ser humano ao mundo exterior se dá através do movimento humanizado e socializado, conseguindo dessa forma dar uma significação a esse mundo.

Para Wallon o ser humano estrutura seu pensamento a partir do ato. E Jean Piaget afirma que a influência recíproca entre o indivíduo e o meio ambiente leva à evolução do desenvolvimento, e que é através do movimento que se processa a relação entre o corpo e a mente.

É através do movimento que o homem responde às significações das situações e do meio, descobrindo esse mundo exterior.

Assim o movimento deixa de ser encarado sob uma ótica mecanicista, estando ligado à cultura. $\mathrm{O}$ ser humano torna-se um ser criador, que dá significação a essa criação através do movimento. Segundo Vitor da Fonseca (1998, p.198) "O Homem existe no mundo como uma unidade e uma totalidade, não como um corpo animado [...]".

Entendendo tudo isso, chegamos à compreensão da relação do movimento com o desenvolvimento do ser humano e da sua ligação direta com a aprendizagem.

\section{A relação do corpo com o desenvolvimento da criança}

Inicialmente o corpo é peça chave no desenvolvimento da criança. A noção de esquema corporal não depende somente da atividade motora, mas está diretamente ligada com os aspectos emocionais e as primeiras experiências sociais da criança realizam-se 
através do seu corpo e do corpo das pessoas significantes para ela.

O esquema corporal é muito estudado pela Psicanálise como influência no desenvolvimento do eu. A junção do eu psíquico com o eu corporal é que constrói no seu humano o sentimento do eu.

A criança percebe os seres e as coisas que a cercam em função da sua pessoa e sua personalidade se desenvolverá graças à tomada de consciência do seu corpo. Ela se sente bem, na medida em que seu corpo lhe obedece e à medida que ela o reconhece podendo utilizá-lo não somente para movimentar-se, mas também para agir.

Para a criança todas as necessidades, pulsões e emoções são exprimidas pelo corpo, não podendo haver concepção de vida do corpo separada do psiquismo.

Segundo FONSECA (1973) O corpo da criança em movimento é o que a envolve no mundo. Ele não é instrumento e sim ela própria no mundo.

\section{Motricidade e psicomotricidade}

Motricidade é o domínio do corpo, agilidade, destreza e capacidade de locomoção voluntária. A psicomotricidade por sua vez, tem como objeto de estudo a ligação entre a motricidade e o psiquismo, bem como o desenvolvimento global do indivíduo na área educacional, pedagógica e de saúde.
A evolução da psicomotricidade, inicialmente fixou-se, sobretudo no desenvolvimento motor da criança. Depois a relação entre o atraso do desenvolvimento motor e o atraso intelectual da criança foi o foco de estudo da psicomotricidade. Hoje a posição é a de ultrapassar os problemas motores e trabalhar a relação entre o gesto e a afetividade, bem como a qualidade de comunicação e aprendizado por intermédio dos mesmos. É a de justificar o movimento como realização intencional, como expressão de uma personalidade.

$\mathrm{Na}$ psicomotricidade o indivíduo é trabalhado como ser físico e social em constante transformação e interação com o meio, modificando esse meio e sendo modificado por ele.

As fases do desenvolvimento psicomotor são dividas em: primeira infância (0 a 3 anos) e segunda infância (3 a 7 anos), completando-se por volta dos oito anos de idade.

A psicomotricidade tem como objetivo fazer do indivíduo um ser de comunicação, de criação e de pensamento operativo.

[...] a partir das primeiras experiências psicomotoras que a criança vai constituindo pouco a pouco seu modo pessoal de ser, de sentir, de agir e reagir diante dos outros, dos objetos e do mundo que a rodeia, e a qualidade da relação que a criança estabelece com o meio é que condicionará a saúde mental da mesma (LAPIERRE, 1984, p. 20). 


\section{As dificuldades de aprendizagem}

A aprendizagem tem sido estudada durante muitos anos e é considerada como o comportamento mais importante dos animais superiores. Faz-se necessário o estudo sobre o processo de aprendizagem para falarmos sobre as dificuldades de aprendizagem.

É um campo muito complexo, controverso e constitui uma mudança de comportamento que vem propriamente como resultado da experiência.

É uma resposta interiorizada e consolidada no cérebro do indivíduo. É uma relação entre $\mathrm{o}$ indivíduo $\mathrm{e} \quad \mathrm{o} \quad$ seu envolvimento resultando uma adaptação de comportamento.

Várias teorias têm tentado esclarecer a problemática da aprendizagem. Entre elas estão, as teorias conexionistas estímuloresposta, a Gestalt que defende a aprendizagem como relação interiorizada de significação entre estímulo e resposta. E a teoria do condicionamento operante, que defende a idéia de que a aprendizagem reflete-se na mudança de comportamento. Temos também teorias como a de Hebb, que defende a aprendizagem como o resultado de interações interneurais e de mudanças sinápticas.

Alguns investigadores como Luria e Vygotsky afirmam que o comportamento deve ser encarado como um sistema funcional que organiza reflexos, sensações, emoções, percepções de origem sócio-histórica.

A aprendizagem é tarefa central do desenvolvimento da criança e visa a utilização de todos seus recursos (interiores ou exteriores), de modo a garantir uma adaptação psicossocial no maior número de circunstâncias possíveis onde são levados em conta os fatores: neurológicos, sócio-culturais e psicoemocionais.

Essa adaptação só é possível quando existe um equilíbrio entre todas as variáveis. Verificamos, portanto, que a aprendizagem é um fenômeno adaptativo complexo que influencia e sofre influência pela interação de todos os fatores citados e a dificuldade de aprendizagem é justamente a falha em alguns desses fatores.

Com isso temos o reforço da importância da relação do corpo com a aprendizagem e a não aprendizagem. Fica mais evidente a noção de que a aprendizagem perde a dimensão mecanicista e valoriza o movimento humano como ferramenta para sanar as dificuldades de aprendizagem.

A dificuldade de aprendizagem não engloba qualquer perturbação da inteligência, da personalidade, nem qualquer anomalia sensorial e motora.

A criança com dificuldade não é deficiente, mas independente de ter uma inteligência, visão, audição e motricidade adequadas, não conseguem aprender normalmente. Este aspecto é fundamental 
para que possamos compreender esse grupo de crianças.

O perfil psicomotor da criança com dificuldade de aprendizagem é afetado apresentando problemas associados à lateralização, direcionalidade e imagem do corpo. As dificuldades de aprendizagem podem ser primárias e secundárias. As primárias englobam as disfunções cerebrais, problemas perceptivos e psicomotores. Já as secundárias englobam as doenças biológicas, problemas de comportamento e fatores socioeconômicos.

Os campos dos sinais neurológicos difusos associados à motricidade e à psicomotricidade têm sido estudados intensamente nas crianças com dificuldade de aprendizagem. Os problemas psicomotores são mais evidenciados que os problemas motores nessas crianças e estão associados a problemas cognitivos bem como afetivos.

A criança com dificuldade de aprendizagem acusa problemas na organização motora de base e conseqüentemente na organização psicomotora.

O movimento, quando na esfera psicomotora [...] compreenderá a integração e relação inteligível de múltiplos dados internos e externos que vão estar na sua elaboração, planificação, regulação, controle e execução (FONSECA, 1998, p. 204).
No início do desenvolvimento humano a motricidade antecede a psicomotricidade e só mais tarde a atividade motora é absorvida pela atividade mental transformando-se em psicomotricidade. Com isso a psicomotricidade traduz a organização neuropsicológica que serve de base para todas as aprendizagens do ser humano.

A organização psicomotora resulta da integração dos dados posturais e motores no movimento, tornando-o um projeto psíquico intrínseco.

Portanto faz-se necessário a identificação pedagogicamente eficiente por parte dos profissionais, para que os problemas não se agravem com a evolução escolar.

O ensino primário é apontado como o lugar mais conveniente para a identificação para uma intervenção preventiva nos parâmetros de desenvolvimento da linguagem, da psicomotricidade, percepção auditiva e visual e o comportamento emocional.

\section{A psicomotricidade como recurso educativo}

A psicomotricidade pode ser utilizada como meio educativo sanando vários problemas junto à leitura, escrita, bem como no raciocínio lógico. A educação pelo movimento deveria ter seu espaço valorizado principalmente na educação primária. 
As estruturas da criança passam por um processo sucessivo de maturação para atingir graus cada vez mais elaborados. E seu organismo não sofre passivamente as leis da maturação e da experiência. Com isso percebemos que a criança recria o mundo e procura atuar nesse mundo de forma ativa com sua capacidade de criação.

A psicomotricidade mostra que é indispensável educar movimento e mente e procura trabalhar o corpo e a mente, relacionando a afetividade ao pensamento e à inteligência. "A integração sucessiva da motricidade implica a constante e permanente maturação orgânica [...] " (FONSECA, 1998, p. 162).

Portanto o desenvolvimento intelectual da criança, sua capacidade de conceber e reconstruir o conhecimento estão diretamente ligados ao domínio e uso do seu corpo. E disso dependem também as relações com as pessoas ao seu redor.

Nos primeiros anos da criança na escola, principalmente no período de alfabetização, uns dos requisitos mais importantes é o uso da mão para escrever. Nem todas elas têm consciência de suas mãos, não as percebe internamente. $\mathrm{O}$ ato de ler $\mathrm{e}$ escrever são complexos e envolvem também outras partes do corpo, sendo assim o desenvolvimento das habilidades não deverá ser incompleto para que a criança não venha a ter problemas de aprendizagem.
A criança deve ser estimulada a trabalhar com o corpo, a percebê-lo internamente e externamente. Tomar consciência de que ele funciona como um todo integradamente.

É importante que o profissional norteie seu trabalho respeitando cada fase de desenvolvimento da criança.

\section{A psicomotricidade na prevenção das dificuldades de aprendizagem}

É de fundamental importância que haja uma estimulação do desenvolvimento psicomotor para que a criança adquira uma consciência dos movimentos corporais integrados com sua emoção. Essa estimulação dos aspectos do desenvolvimento deve ser feita desde o nascimento até os 8 anos de idade aproximadamente. As principais dificuldades de aprendizagem que trazem prejuízos no desenvolvimento da escrita, leitura e fala se instalam nesse período. Por isso a necessidade de se trabalhar preventivamente e a tempo o estímulo do desenvolvimento psicomotor.

As capacidades básicas são refinadas após esse período e isso só torna-se possível apenas com a integridade das condutas motoras, intelectuais e emocionais da criança.

$\begin{array}{lrr}\begin{array}{l}\text { Defendemos através da } \\ \text { nossa concepção } \\ \text { psicopedagógica, }\end{array} \\ \text { inseparabilidade } & \text { do } \\ \text { movimento e da vida } \\ \text { mental (do ato ao } \\ \text { pensamento), estruturas }\end{array}$


que representam o resultado das experiências adquiridas, traduzidas numa evolução progressiva da inteligência, só possível por uma motricidade cada vez mais organizada e consciencializada

(FONSECA, 1977, p. 312).

A psicomotricidade auxilia tanto na prevenção como no tratamento das dificuldades de aprendizagem. E vai, além disso, explorando o potencial ativo da criança.

É necessário que a criança seja levada a romper com suas barreiras corporais, através da vivência do seu corpo. Podendo descobrir, sentir, interiorizar, enfim, conceber seu corpo.

$\mathrm{O}$ processo de aprendizagem vem da relação com a situação concreta, consciente e inteligível que se transforma numa ação intencional fruto da junção do movimento e da vida mental.

Cabe notar que a prevenção dos problemas de aprendizagem através do estímulo do desenvolvimento psicomotor é válida e deve ter como objetivo a evolução da personalidade da criança, proporcionando atitude, permitindo a aquisição de condutas e a melhora da apreensão do real. Deve proporcionar à criança a inovação e a criatividade pessoal, bem como a possibilidade de auto-análise no seu processo de aprendizagem.

\section{Considerações finais}

Fica evidente a consciência que a psicomotricidade nos traz de que o movimento humano tem um caráter intrínseco e que todo reflexo, mesmo o mais simples, é sinônimo de vida subjetiva, assim como todo pensamento implica, requer, certa organização motora.

A psicomotricidade nos mostra que o psíquico e o motor não estão separados. Eles são a mesma coisa, no mesmo tempo. É a ligação do que o corpo vive de forma subjetiva com o que executa de forma objetiva. Ela está presente em todo o processo de aprendizagem, bem como exercendo um papel importantíssimo de prevenção e intervenção nas dificuldades de aprendizagem. Leva-nos a refletir no sentido de modificar e repensar toda a dinâmica escolar, que deve estar sempre dando a devida importância à individualidade do aluno, tomando como base a totalidade do seu desenvolvimento.

A escola antes de se preocupar em cumprir programas e atingir resultados, deve dar prioridade ao desenvolvimento global da criança, solicitando-lhe a sua pré-disposição criadora, não impondo o que deve pensar ou fazer de forma mecânica. Ela não pode tornarse uma instituição acumuladora de dificuldades, mas deve buscar recuperar a valorização do ser humano como criador e renovar-se através de uma nova ótica que busca resgatar o prazer da cultura vivida, tão esquecida nos tempos atuais. 


\section{Bibliografia}

BUENO, Jocian Machado.

Psicomotricidade: teoria e prática. Editora

Lovise, 1998.

FONSECA, Vitor da. Contributo para o

estudo da gênese da psicomotricidade. 4 .

ed. Lisboa: Editorial Notícias,1977.

Uma introdução às dificuldades de

aprendizagem. Lisboa: Editorial Notícias, 1984.

Psicomotricidade: Filogênese,

ontogênese e retrogênese. 2. ed. Porto Alegre:

Artes Médicas, 1998.

LAPIERRE, André; AUCOUTURIER, Bernard. Fantasmas corporais e práticas psicomotoras. São Paulo: Manole, 1984.

A simbologia do movimento, psicomotricidade e educação. São Paulo:

Manole, 1986. 